\title{
Deep Myofascial Kinetic Lines in Horses, Comparative Dissection Studies Derived from Humans
}

\author{
Vibeke Sødring Elbrønd1 ${ }^{*}$, Rikke M. Schultz ${ }^{2}$ \\ ${ }^{1}$ Faculty of Health \& Medical Sciences, Copenhagen University, Copenhagen, Denmark \\ ${ }^{2}$ RMS Equine Practice, Kokkedal, Denmark \\ Email: *vse@sund.ku.dk, rms@rikkeschultz.dk
}

How to cite this paper: Elbrønd, V.S. and Schultz, R.M. (2021) Deep Myofascial Kinetic Lines in Horses, Comparative Dissection Studies Derived from Humans. Open Journal of Veterinary Medicine, 11, 14-40. https://doi.org/10.4236/ojvm.2021.111002

Received: November 29, 2020

Accepted: January 26, 2021

Published: January 29, 2021

Copyright $\odot 2021$ by author(s) and Scientific Research Publishing Inc. This work is licensed under the Creative Commons Attribution International License (CC BY 4.0).

http://creativecommons.org/licenses/by/4.0/ (c) (i) Open Access

\begin{abstract}
Seven superficial myofascial kinetic lines have been described earlier in horses in a comparative dissection study to the human lines. The lines act as an anatomical basis for understanding locomotion, stabilization, and posture. Further dissections verified three profound equine lines comparable to those described in humans and a fourth line not described previously. Forty-four horses of different breed and gender were dissected, imaged and video recorded. The horses were euthanized due to reasons not related to this study. A Deep Ventral Line (DVL) very similar to that in the human was verified in these studies. The line spans from the insertion of the profound flexor tendon in the hindlimb to the base of the cranium and oral part of the cavities of the head. It includes the profound, hypaxial myofascial structures, the ventral coccygeal muscles, the psoas muscles, the diaphragm, the longus colli/capitis muscles and the ventral capital muscles. The inner lining of the pelvic, abdominal and thoracic cavities with all the organs, vessels and nerves are also included. The line is closely connected to the autonomic nervous system by the vagus nerve, the pelvic nerves, the sympathetic trunk and several of the prevertebral nerves and ganglia. The new line identified in this study, is a Deep Dorsal Line (DDL), which starts in the dorsal tail muscles. It comprises myofascial structures of the spinocostotransversal system from the tail to the head including the nuchal ligament. It connects to the dura mater and has a major role in controlling the motion and stabilization of the Columna vertebralis. Both the DDL and the DVL include the coccygeal myofascia and periosteum of the skull. Due to differences in biped and quadruped anatomy the Front Limb Adduction Line (FADL) and the Front Limb Abduction Line (FABL) differ from the human lines. The lines are identified as slings in the brachial and antebrachial regions. The FABL includes structures for abduction
\end{abstract}


and internal rotation connecting to the Front Limb Retraction Line (FLRL), and the FADL structures of adduction and external rotation in close proximity to the Front Limb Protraction Line (FLPL). The front limb lines support the movement of the front limb around the "thoraco-scapula pivot joint" medially at the level of the upper third of the scapula. The DVL identified in this study is similar to the human DFL whereas the front limb lines differ somewhat from the deep human arm lines due to differences in bi- and quadruped anatomy and biomechanics. We have identified and described this new equine DDL. The lines altogether explain a profound body balance and confirm the three-dimensional equine fascial network, which is of great clinical and biomechanical importance.

\section{Keywords}

Myofascial Lines, Deep Ventral Line, Deep Dorsal Line, Deep Adduction

Line, Deep Abduction Line, Viscero-Somatic Connections

\section{Introduction}

Seven superficial equine myofascial kinetic lines consisting of long rows of interconnected anatomical structures have earlier been described and published by Elbrønd and Schultz [1]. The lines are composed of integrated muscles and fascia and are arranged in long rows spanning from the head to the hoofs in the equine body. Each line is responsible for connecting movements between the spine and the extremities e.g. the Superficial Dorsal Line extends the spine and flexes the hind limbs, and the Superficial Ventral Line flexes the spine and extends the hind limbs. The structures of the lines serve to functionally direct basic locomotion patterns, support the musculoskeletal system as well as balance and describe the posture and motion of the whole body. In addition, these lines are essential if one is to fully understand the basic anatomy of the whole body and especially such generally accepted concepts as head to hoof and latero-lateral connections and their integrations in the horse. The human equivalents, the myofascial anatomy trains, composed of interconnected muscles, tendons and fascia, have already been dissected and described by Myers [2]. Besides the seven human superficial trains, equivalent to the already published equine lines [1] [2] another three profound lines are presented. These three lines are all situated profound, that is to say deep, within the body where they complement the seven superficial lines. Myers, [2], identifies one line as passing through the body cavities connecting the somatic body with the viscera, the Deep Front Line, as well as two deep lines in the arms. In the horses the corresponding lines are the Deep Ventral Line (DVL) and two lines related to front limb motion. These latter complement the already dissected Front Limb Protraction (FLPL) and Front Limb Retraction Lines (FLRL) [1]. In our opinion a deep dorsal line, complementary to the DVL seems to be lacking in the horse. Therefore, we 
additionally focused on a Deep Dorsal Line situated in the deep epaxial back muscles.

Biomechanically and structurally the Human Deep Front Line is essential in balancing the spine through the hypaxial muscles. With the presence of this line Myers [2] has established an understanding of the connection between the fascia lining of the inner body cavities and the organs, to extensions into profound myofascial structures in the directions of the head, neck and limbs. Connections between somatic and visceral systems have been discussed in relation to many topics, e.g. viscero-somatic reflexes based on integration in the nervous system, and indeed viscero-somatic pain [3]-[12]. A new approach in this respect is raised by the findings by Stecco et al. [13] in a histological study of the subserosal fascia related to the inner organs. Here the group found that the subserosal fascia can be divided into two major groups, the investing fascia, and the insertional fascia. The latter is characterised by sheets forming the compartments to the organs, being composed of several layers of larger bundles of collagen fibres, including both smaller and myelinated large diameter nerves. According to Stecco et al. [13] the presence of such nerves indicates a connection between the insertional fascia and the somatic/musculoskeletal parts of the body. The insertional type of fascia is present both in relation to the pericardium, the abdominal organs and very distinct around the kidneys. A deeper layer of subserosal fascia, named the investing fascia, organizes, and shapes the organs and supports the parenchyma. It is elastic and rich in small blood vessels and small diameter nerves. The thickness and presence of the two types of layers differs between organs.

Significant differences are present in the anatomy and motion of the arm/front limb between the horse, which has a quadruped posture and that of the human with its biped posture. The four human arm lines [2] comprise all the major motions over the full length of the arm. In the horse, however, the front limbs are constructed for stable movement at low energy costs which is only possible due to specifically designed myofascial structures. These features are clearly reflected in the anatomy of the front limb, which from the elbow and distally are specifically addressed to flex and extend and perform protraction and retraction movements. The only exception is the coffin joint presenting very limited abduction/adduction and internal/external rotation.

The equine FLPL and FLRL [1] clearly reflect these movements but descriptions of lines addressing the ab- and adduction as well as in- and external rotation (pro- and supination in humans) [14], are clearly missing in the horse. Due to the anatomy of the limb from the elbow and distally including hinge joints and fusion of the antebrachial bones [15] [16], only myofascial structures in the proximal part of the front limb are involved in such movements. Indeed, this indicates that the deep arm lines are located around the scapula, humerus and the thoracic sling (e.g. m. serratus ventralis and $\mathrm{mm}$. pectoralis).

To understand the context of the myofascial connections of the myofascial lines Yucesoy et al. [17] explain in their study that intact muscles with endo-, 
peri- and epimysial linings do not work as isolated structures. Due to the 3-D fascia skeleton they are to be dealt with as linked and connected units with properties designed for force transmission, energy loading and energy conservation as well as shock absorption. Several research groups present this feature in both rats and humans, in intact muscles in vivo, and in muscles detached from the intermuscular fascia connections. These results change the up to now stated biomechanical interpretation of the relation between muscles as being agonists—antagonists—synergist etc. [18] [19] [20] [21] [22], and opens the door for a new perspective on the functional muscle-fascia interactions which also include an integration of the full body.

Conjoined with a development of the locomotory system and motion patterns the body adapts the engaged structures e.g. muscles, bones and the fascia/myofascia. The concept "fascia plasticity" describes a reflexion and adjustment of not only the fascia/ myofascia and myofascia lines based on the principle of "Supply and demand". A biomechanically induced tension in myofascial structures can induce adaptations of e.g. deposition of collagen fibres along the lines of tension thereby adjusting the strength between muscle groups, fascia sheets etc. [23]. The fascia can adapt in other ways, at different levels and with different time frames. At the cellular level the fibroblasts can contract within a matter of minutes [24] [25] [26] [27] and at the macroscopic level an increased deposition of collagen fibres, as mentioned above, within a significantly longer time period. This latter process is initiated by only a few repetitions of tensions "over the load" [28]. With ongoing tension, renewal of the collagen fibres in a healthy human occurs within six months [29]. Indeed, a rough extrapolation from these data estimates the intrafascial dynamics with a time frame of replacement of 30\% within six months and $75 \%$ within two years in humans [24]. When loading myofascia, the interplay and the exchange of tension between the muscles and fascia favours a smooth and elastic loading which protects the fascia and keeps it "fit" and supple. Younger individuals seem to possess a high degree of flexibility and elasticity of their fascia, a phenomenon seen and explained by the histological architecture and organization of the collagen fibres [30]. The fibre bundles are found to undulate in a wavy pattern ("the crimping effect") and elastic fibres arranged as an interwoven network provide a structure that enables lengthening without overstretching the collagen fibres. Initially such loading results in lengthening, but subsequently it allows the collagen fibres to regain their original organization, supported by the elastic fibres [31] [32]. Thus, in this way fascial plasticity supports the body in several ways to adapt to acute and more permanent tensional changes.

The myofascial kinetic lines are arranged and overlapping one and another. Therefore, mobility and flexibility are essential for the lines to interact and to balance the body. Loose irregular connective tissue containing high amounts of hyaluronan (HA) meets this demand and is situated between and on surfaces of muscles, myofascia, aponeuroses, fascia layers as well as many other vital structures such as nerves, blood and lymph vessels etc. [32] [33]. The tissue 
lubricates and makes the surfaces slippery and maintains the vital movements e.g. in the locomotion system, including the myofascial lines. In human specimens, Stecco et al. [34] [35] identified not only the presence of HA but also HA secreting fasciacytes, which they assume to be specialized fibroblast-like cells of monocyte/macrophage like origin. Recently, the presence of HA between the fascia layers has been confirmed at the microscopical level in horse specimens [33]. Moreover, the conformation of HA is known to influence the capability of structures to move in relation to each other, with changes in the HA-matrix leading to an inhibition/change in movements, the induction of pain and inflammatory conditions which then lead to more pathological conditions [36].

The aim of this study was to reveal the inter-connective functionality of the locomotor system of the profound lines in the horse in continuation with the superficial lines previously described by [1]. This study has therefore been performed to verify and support our three hypotheses; 1 ) there exists a deep line of interconnected myofascial and visceral fascia in the horse comparable to the human Deep Front Line. The Deep Line presents connections between the somatic body and the organs, 2) there are two deep equine front limb lines, equivalent to the deep arm lines in humans, despite the anatomical and functional differences in the front limbs of these two species, and 3) there exists an Equine Deep Dorsal Line, which serves to establish a balance around the vertebral column, the tail and the head.

\section{Methods}

\subsection{Horses}

In total forty-four horses of different breeds, aged ( 2 - 31 years) and of both sex (19 mares and 25 geldings), e.g. riding horses, ponies, and Icelandic horses were combined in this study. Forty-one (41) of these horses were dissected to test the hypotheses and isolate and describe the deep lines. Three of the horses were frozen and segmentally sectioned in transverse sections. All the horses were euthanized for reasons unrelated to this study. The horses were either from private owners in a radius of $60 \mathrm{~km}$ from Copenhagen City, or in a few cases (approx. 4 - 5) were horses bought from a slaughter house north of Copenhagen for teaching purposes.

Copenhagen University, Faculty of Health \& Medical Sciences, Pathobiological Sciences not only approved this project but also provided facilities and monitored its progress.

\subsection{Dissection Methodology}

\subsubsection{Pre-Dissection Approach}

The profound human lines (Myers 2013) were transferred from the bi- to the quadruped posture and the specific Equine Anatomy outlined from intense theoretical studies of the literature [15] [16] [37] [38] thereby creating the best possible map of the equine lines. 
The entry angle to the DDL was based on practical experiences coupled to theoretical studies of the anatomy [15] [16] [37] [38].

\subsubsection{Practical Aspects of the Dissection}

After euthanization, the dissections were performed on skinned horses following the specific rules of the lines as stated by Myers [2], 1) The lines of tension (collagen fibre bundles) in any given line should be aligned in the same functional direction, 2) The structures are to be situated at the same level of the body, 3) The span of the myofascial structures, specifically has to be over more than a single joint, and 4) The overall function of the structures in every line must be similar [1].

The horses were arranged in different positions (hanging by their hind legs, hanging in a standing position, lying on their side, prone or on their back) to approach the different parts and regions of the lines. Direct, stump and interactive dissection techniques were used to follow and isolate myofascial connections and the lines (Elbrønd and Schultz, 2015). Adjustments to the theoretical approach for the lines were done accordingly. For dissecting specific parts of the DVL the abdominal and thoracic cavity were eviscerated fully or partly and the pubic bone was removed.

\subsubsection{Transverse Sections}

For the transverse sections the horses were euthanized, shaved and the gastro-intestinal-tract was removed. The horses were marked segmentally along the spine and positioned either hanging by their legs or lying prone on a table before being frozen at $-20^{\circ} \mathrm{C}$ for a week. The horses were finally cut into segments using a bandsaw and the segments were kept separated until they were photographed for more detailed image analysis.

\subsubsection{Photography}

A Ricoh camera GX200 (Ricoh Company, Ltd, China) and a PowerShot G1X, Mark II camera (Canon Inc., Japan), were used for recording and photographing the dissections and the isolated lines, whilst a Canon EOS 6000D camera (Canon Inc, Japan) was used for recording the painted, live horses. The images were edited using Photoshop Cs3 and Cs4 software (Adobe Systems Inc. USA). The paint used was theatrical face paint, Grimas (2001 De Haarlem, the Netherlands).

\section{Results}

The results of the dissections will be described in detail for each and every line.

\subsection{Deep Ventral Line (DVL)}

The deep ventral line is illustrated in Figure 1(a) and Figures 2(a)-(d).

The line corresponding to the human Deep Front Line is named the Deep Ventral Line (DVL) and the description and dissections have been adjusted for the anatomy of the equine quadruped. 


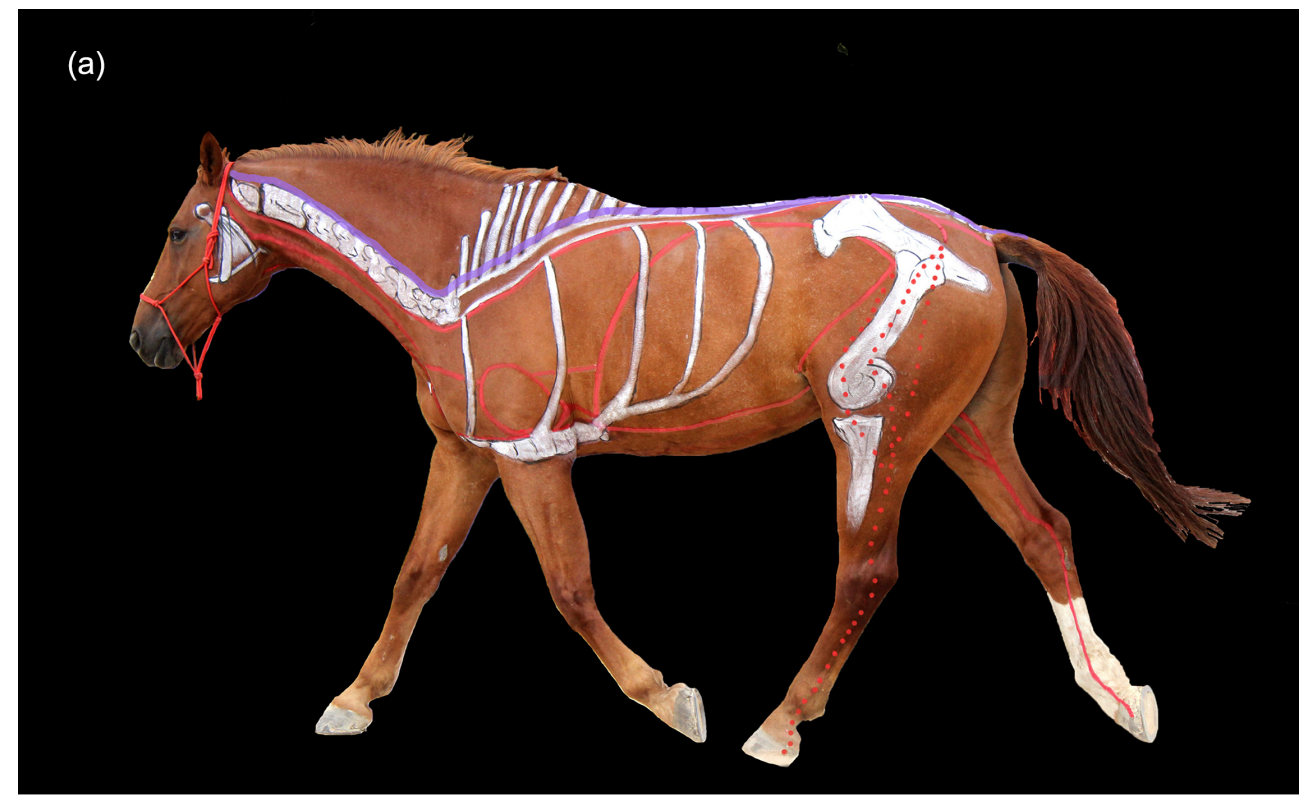

(b)

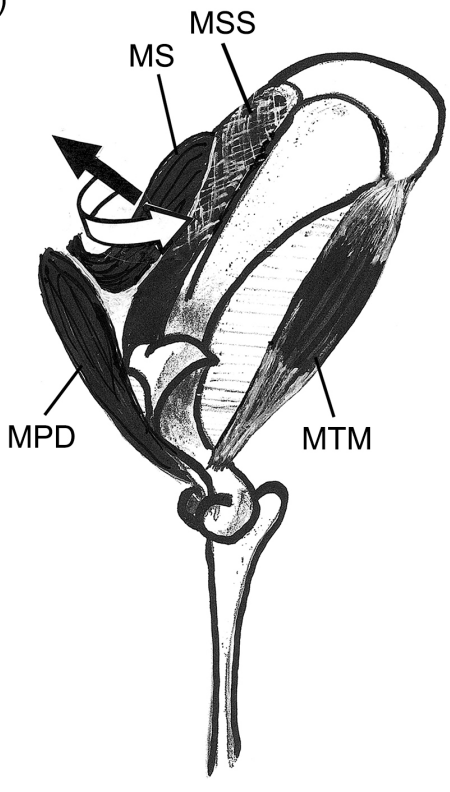

(c)

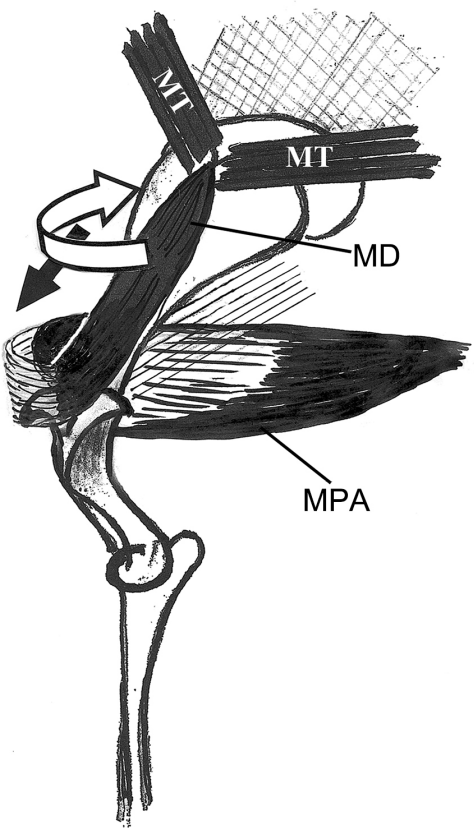

Figure 1. (a), (b) and (c) present an overview of the deep equine myofascial kinetic lines. (a) An overview of the DDL (purple) and DVL (red) myofascial kinetic lines painted on a horse. The pathways of the DVL from the distal end of the hindlimbs into the pelvic cavity, further on into the abdominal and thoracic cavity and finally along the neck towards the head are all outlined. The DDL is situated epaxial from tail to head along the vertebral column. The two lines serve to balance around one another, either side of the Columna vertebralis, (b) illustrates the major myofascial connections of the FADL. The line is defined at the start of the protraction phase and illustrates an adduction of the proximal part of the front limb coupled to an outward rotation. MS ( $M$. subclavius), MSS (M. supraspinatus), MPD (M. pectoralis descendens), MTM ( $M$. teres major). The white arrow illustrates the outward rotation and the black arrow, the adduction; (c) presents the connections in the FABL. This line is defined at the start of the retraction phase presenting the abduction and the inward rotation of the proximal part of the front limb. MT (M. trapezius), MD (M. deltoidus), MPA (M. pectoralis ascendens). The white arrow illustrates the inward rotation and the black arrow, the abduction. 
From caudal the line has two entrances; one which connects the deep adductor and digital flexor muscles of the hind limbs to the pelvic aperture (see the illustration in Figure 1(a)), and another which connects the ventral compartment of the tail with the lining of the inner cavities. Both parts present connections to the inner organs and the muscles of the pelvis, the abdomen and the thorax to the cranium and the nasal and oral cavities.

The part of the line from the limbs starts at the insertion of the common part of the Tendo m. flexor dig. profundus (tendo communis) at the Facies flexoria phalanx distalis. From here the Tendo communis runs plantar to the Bursa podotrochlearis, the Os sesamoideum distale (the navicular bone), the Phalanx medius and proximalis to Os metatarsale III. At the level of the proximal part of the metatarsus the Tendo communis separates into two individual branches which pass medially over the tarsus, Ossa tarsi, heading towards the three capitae of the profound flexor muscle. The muscle bellies originate at the Facies caudalis tibialis and Facies caudalis fibula and Caput fibula. The line continues in a medio-proximal direction towards the stifle where the epimysial lining and fascia from the flexor muscle unites into Fascia genus and the Lig. collaterale mediale of the Articulatio femorotibialis. From here it connects into the myofascia of Mm. adductor major et minor and $m$. pectineus as well as the $M$. sartorius and into the region connecting to the pelvic and abdominal cavities (Figure 2(a)).

The second part of the line starts in the tail in the Fascia cauda. This fascia forms an envelope around the tail and divides it into four compartments: a dorsal, two lateral and a ventral of which the latter is included in the dorsal part of the DVL. Ventrally to the corpora vertebrae, the fascia cauda continues into $M$. sacrocaudalis ventralis medialis et lateralis and the M. coccygeus (Figure 2(a)). It then continues into the intrapelvic fascia structures, the adventitia of the most caudal part of the urogenital tract and the most aboral part of the gastrointestinal tract as well as the fascia lining of the intrapelvic vessels and nerves (e.g. nn. pelvini).

From here the line spreads in a cranial direction and includes all the internal linings, the subserosal fascia and all its derivatives related to the abdominal and thoracic cavities, the inner organs, and structures (see Figure 2(b) and Figure $2(\mathrm{c})$ ). Due to the 3-D aspect of this line and so as to provide a better explanation and understanding of this line, subsequent explanation will focus on three pathways 1) the dorsal, 2) the mid, and 3) the ventral.

1) The most dorsal part of the line from the tail and the pelvic cavity continues in a cranial direction to the Spina ischiadica. From here it moves with the Lig. longitudinale ventrale on the ventral surface of the Os sacrum (Figure 2(a)). This ligament follows the ventral surface of the Columna vertebralis until the 7 - 9th thoracic vertebrae where it joins the myofascia of the M. longus colli and the lamina prevertebralis of the Fascia cervicalis. From here it passes through the Apertura thoracis cranialis and into M. longus capitis at the level of 
C4-C3. It terminates ventrally at the Basis cranii externa (Figure 2(d)) close to the Synchondrosis spheno-basilaris (SBS) between the Os occipitalis and Os sphenoidale.

2) The second and mid pathway, follows $M$. sartorius through Lacuna musculorum into the sheet of Fascia iliaca from M. iliopsoas (see Figure 2(a)). It continues in a cranial direction through $M$. psoas minor and major (Figure 2(a)) to the thoracolumbar junction where it interacts and overlaps with the Crus dexter et sinister of the Diaphragma (Figure 2(b), Figure 2(c)) including also the other muscular (pars lumbalis, costalis et sternalis) and tendinous parts of Diaphragma. In the abdominal and pelvic cavity, the line also includes the subserosal fascia of the Peritoneum visceralis as well as ligaments, plicae and other derivatives related to the urogenital, the mesenterium and the gastrointestinal tract and organs (see Figure 2(c) and Table 1).

The peripheral fascia capsule around the retroperitoneal positioned kidneys and the retropleural positioned heart (the pericardial sac) were found to have the same macroscopic characteristics as the inserting fascia described in humans [13]. These macroscopically identifiable compartments favour the possibility that these organs can move freely yet still remain protected. The insertional fascia layers are also present in close connection to the rest of the abdominal organs and provide the organs with mobility and protection. Generally, the insertional fascia connects the organs to the musculoskeletal system [13]. The connection between the insertional part of the subserosal fascia of the abdominal organs and the locomotion system was clear in several locations. The fascia of the kidneys was found to be closely related to the ventral surface of the vertebrae at the thoracolumbar transition, to the M. psoas major and minor, and to the Fascia transversa of the trunk. The liver fascia connected to the Diaphragma and the $M$. psoas major and minor and the fascia of the $M$. transversus abdominis. Moreover, the other abdominal organs such as the pancreas, spleen, gastro-intestinal tract, urogenital tract, ovaria etc. are provided with an insertional fascia first hand and underneath a layer of investing fascia, which are found to be closely related and connected to the organ mesenchyme and the inner organ architecture. An overview of the subserosal insertional fascial connection to the locomotion system is presented in Table 1.

The cranial continuation of this second pathway enters the thorax and on into the subserosal fascia lining of the mediastinum and the pericardium. Collagenous tension lines are present from the base of the heart and in the dorsal mediastinum with a direction pointing towards the mid thoracic vertebrae (Th 7 - 10). Here the line includes the subpleural fascia enclosing the thoracic organs e.g. the esophagus, the trachea, the lungs, and the heart. An intimate contact is observed with the parasympathetic $N$. vagus, which is situated in the mediastinum from the Apertura thoracis cranialis to the diaphragm. In the closure of the Apertura thoracis cranialis the prevertebral sympathetic ganglions are situated e.g. the Ggl. Stellatum cranially and dorsally under the Costa prima and secunda. 

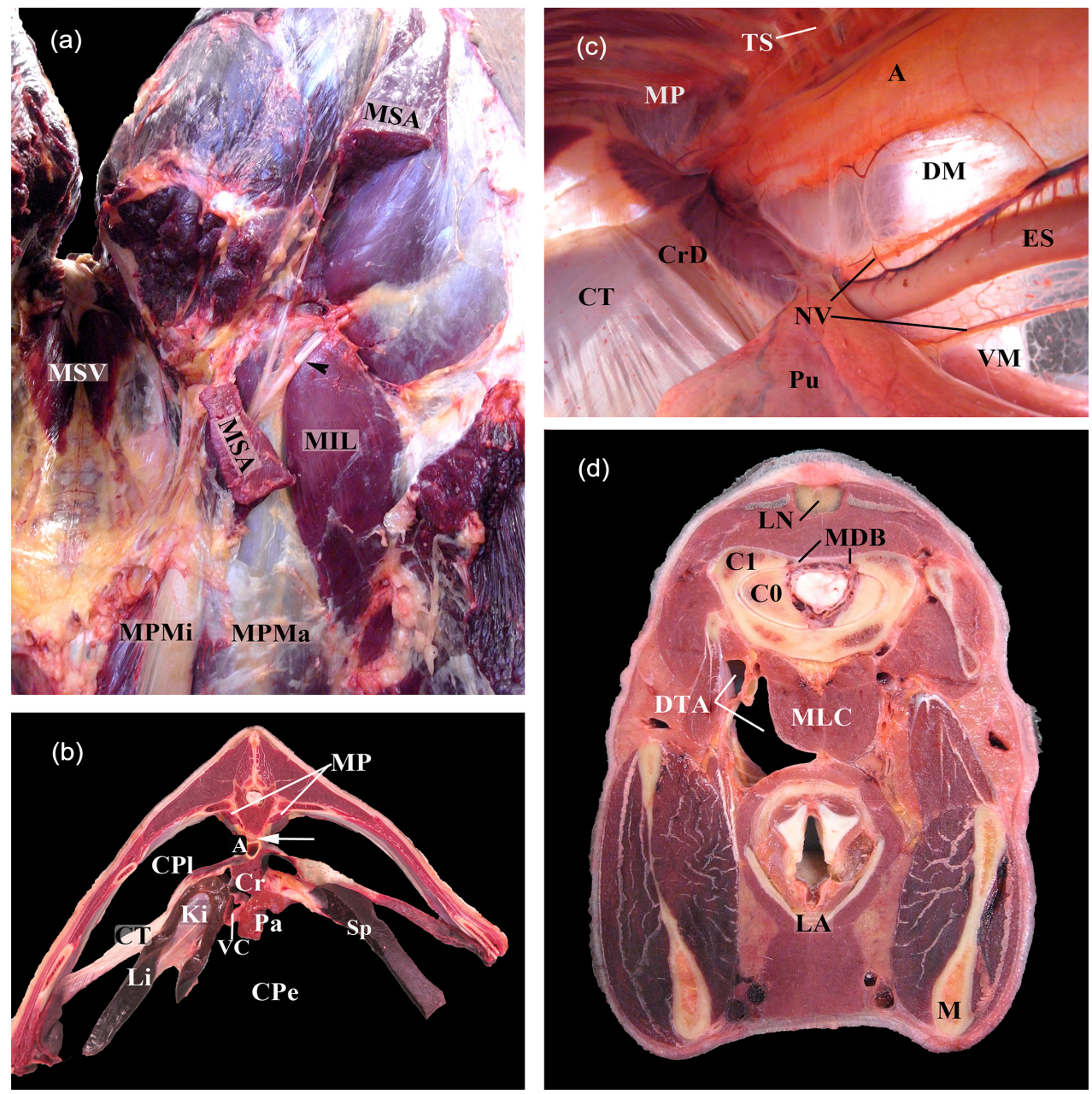

Figure 2. Presents 4 regions of the Deep Ventral Line. (a) Ventral aspect of the pelvic part of the DVL. The ventral surface of the hindquarter (caudal is at the top) with the sacrum (to the left) and the medial surface of the left thigh are presented. Os pubis has been removed. The dorsal entrance of DVL into the cavum pelvis through the ventral tail muscle (M. sacrococc. ventralis (MSV) is on the ventral surface of the sacrum. The middle part enters the pelvis and continues into the abdominal cavity via $M$. sartorius (MSA) (the mid part has been removed) through the fascia of Mm. psoas major and minor (MPMa and MPMi) with the medial part of M. iliacus (MIL) lateral to them. Notice also the $N$. femoralis (black arrowhead); (b) A cranial aspect of a transverse section at the level of Th15. The DVL is covering the whole inner lining of Cavum pleura (CPl) and Cavum peritoneum $(\mathrm{CPe})$ with the organs. Here we see presented the Lig. long. ventralis (white arrow), $M$. psoas $(M P)$, Crus dexter and sinister diaphragmatis $(\mathrm{Cr})$, the subserosal lining of the organs, e.g. in the liver ( $\mathrm{Li})$, the spleen $(\mathrm{Sp})$, the pancreas $(\mathrm{Pa})$, and the kidney (Ki). The diaphragm is also included here with Centrum tendineum diaphragmatis (CT) together with the Aorta (A) and Vena cava (V); (c) A craniocaudal aspect of the right part of the cavum pleura. The mid part of the DVL is richly represented as the subserosal layer of lamina visceralis of the Pleura, which overlay the majority of the presented structures. Caudodorsally, the overlap between the Mm. psoas (MP) and the Crus of the diaphragma (Crus dexter $(\mathrm{CrD})$ is visible. Pulmo (Pu), Dorsal mediastinum (DM), Ventral mediastinum (VM), Nervus vagus (NV), Truncus sympaticus (TS), Esophagus (ES) and Centrum tendineum $(C T)$; (d) A transverse section at the $\mathrm{C} 0 \mathrm{C} 1$ transition. All three levels of the DVL are presented as well as the cranial part of the DDL. The DVL comprises all structures ventral to the vertebrae $(\mathrm{C} 0 \mathrm{C} 1)$ and the mandible $(\mathrm{M})$ as the lateral borders: M. longus capitis (MLC), Larynx (LA), Diverticulum tuba auditiva (DTA). The epaxial structures: Ligamentum nuchae (LN), the Myodural bridge (MDB) and the local epaxial muscles are all contributory to the DDL. 
Table 1. Overview of some of the major fascia connections between the subserosal insertional fascia and the somatic/locomotor system in the horse.

\begin{tabular}{|c|c|c|}
\hline Organ & Connecting structures & Connections to the somatic/locomot. system \\
\hline \multirow{6}{*}{ Liver } & Lig. triangulare dexter & Diaphragma, Centrum tendineum \\
\hline & Lig. Sinister & M. transversus abdominis and aponeurosis \\
\hline & & Diaphragma pars costalis \\
\hline & Lig. coronarius & Centrum tendineum diaphragmatis \\
\hline & Lobus caudatus, proc. caud. & M. psoas major et minor \\
\hline & Lig. teres hepatis/falciformis & $\begin{array}{l}\text { M. rectus abdominis } \\
\text { (the ventral part of Diaphragma) }\end{array}$ \\
\hline \multirow{2}{*}{ Stomach } & Esophagus/Cardia, & The ventral part of the crus dexter diaphragmatis \\
\hline & Omentum majus, lig. Gastrophrenicum & Centrum tendineum, crus sinister diaphragmatis \\
\hline
\end{tabular}

Intestinal tract

Intestinum tenue

Mesoduodenum, jejunum, ileum

Caput caecum

Adventitia
Intestinum crassum

M. psoas minor/major, Crus dexter/sinister diaphragmatis

Mm. psoas major et minor dexter,

M. transversus abdominis

M. sphincter ani externus

$M$. levator ani

M. sacrococc. ventralis

Indirectly to M. biceps femoris via connection to Lig. sacroiliaca

\begin{tabular}{ll}
\hline Lien/spleen & Omentum majus, Lig. phrenicolienale \\
\hline Gl. adrenales & Adventitia \\
\hline Kidney & $\begin{array}{l}\text { Subserosal fascia, dorsal part of the } \\
\text { capsula adiposa, trabecular attachments } \\
\text { from the capsula fibrosa renalis }\end{array}$
\end{tabular}

\begin{tabular}{ll} 
Ureteres & Adventitia \\
\hline $\begin{array}{l}\text { Subserosal fascia of Processus vaginalis } \\
\text { Mesovarium }\end{array}$
\end{tabular}

Ovarium

Lig. ovarii proprii

Subserosal fascia of Processus vaginalis and mesorchium

Testis

Proximal connections from the site of origin, mesonephros

\begin{tabular}{lll}
\hline \multirow{2}{*}{$\begin{array}{l}\text { Vesica urinaria } \\
\text { Ligg. vesicae lateralis } \\
\text { Lig. vesicae mediana }\end{array}$} & $\begin{array}{l}\text { M. transversus abdominis } \\
\text { Fascia rectus, } M . \text { rectus abdominis }\end{array}$ \\
\hline \multirow{2}{*}{ Uterus } & Lig. latum uteri & $\begin{array}{l}\text { Mid part of } M . \text { transversus abdominis } \\
\text { Lig. teres uteri }\end{array}$ \\
& $\begin{array}{l}\text { Mm. obliquus internus, externus and transversus } \\
\text { abdominis } \text { and Anulus inguinalis }\end{array}$
\end{tabular}

Centrum tendineum, crus sinister diaphragmatis

Mm. psoas major and minor, prox part

Mm. psoas major et minor

M. transversus abdominis

Diaphragma pars lumbalis

Crus dexter diaphragmatis (right kidney)

Ventrally along the Mm. psoas major and minor

Mm. obliquus internus, externus and transversus abdominis via Anulus inguinalis

Via the Lig. latum uteri and to the M. transversus abdominis and ventral surface of $\mathrm{Mm}$. psoas major and minor

Mm. obliquus internus, externus and transversus abdominis via Anulus inguinalis

Connections alongside the $A$. testicularis to $M m$. psoas major and minor to the offspring from the Aorta, cranial to the kidney

M. transversus abdominis

Mm. obliquus internus, externus and transversus abdominis 
The line continues in the Cavum thoracis through the Apertura thoracis cranialis and follows along the Trachea and Esophagus in the Fascia cervicalis, lamina pretrachealis to the ventral cervical region. The fascia arranges bilaterally into a right and a left Vagina carotis, which include the A. carotis communis, $V$. cava cranialis, the Truncus vagosympaticus and the N. recurrens. At the Apertura thoracis cranialis the line also comprises $M$. scalenus from the Costa prima to C4-C7 (the ventral part) and to C7 (the middle part) between which the Plexus brachialis passes through. The right and left Mm. scalenii embrace the trachea. The line continues to the Pharynx, Larynx, Diverticulum tubae auditivae and into the profound masticatory muscles of the oral cavity and the tongue (Figure 2(d)).

3) The third and ventral pathway follows the subserosal lining of the Lamina parietalis of the walls and ventral surface in the Cavum pelvis, abdominis and thoracis (Figure 2(b)). In the thorax, the subpleural fascia also includes the dense and strong Fascia endothoracica. Over the caudal part of the sternum the endothoracic fascia splits and directs dorsally, transforming into the Lig. sternopericardiaca and at the apex of the heart it transforms into the Pericardium fibrosum. From the thorax in a cranial direction the line continues over the Manubrium sterni and through the M. sternohyoideus to the Apparatus hyoideus and the Articulatio temporo-hyoidea. It also continues rostrally through the hyoid muscles inserting at the rostral part of Mandibula and the structures within the Cavum oris (Figure 2(d)). The two latter pathways unite within the Lamina pretrachealis of the Fascia cervicalis.

The function of the DVL is to serve as a flexor and stabilizer of the spine through the hypaxial muscles. The psoas muscles are responsible for the flexion and stabilization of the thoraco-lumbar and the lumbo-sacral region and the longus colli/capitis muscles for the flexion of the cervico-thoracic and the cervico-capital junction. This part of the line also integrates several structural connections of the viscera to the somatic body.

The full line can be divided into three major parts: The two ends (caudal/hindlimb and cranial/neck and head), which include structures mostly related to the somatic part of the body, and the middle part (the abdomen and thorax), which in majority is related to the visceral part of the body.

\subsection{The Deep Front Limb Lines}

In contrast to the FLPL and FLRL [1] the deep front limb lines are arranged as slings and comprise several broad aponeurotic fascia sheets related to the scapular and brachial region. The deep lines are focused around the pivot joint in the upper third of the scapula similar to the pro- and retraction front limb lines.

The Deep Front Limb Lines are illustrated in the Figure 1(b), Figure 1(c) and Figures 3(a)-(d).

\subsection{The Front Limb Adduction Line (FADL)}

The FADL starts at the Margo cranialis et Facies cranio-dorsalis scapula with the 
M. subclavius and $M$. supraspinatus. The line follows these muscles towards the Sternum accompanied by $M$. pectoralis descendens and M. pectoralis transversus from Os humeri. Just proximal to the Articulatio humeri at the transitional zone between the scapula and the brachium and on the medial side, is a broad fascia connection which is present between M. subclavius and M. teres major (Figure 3(d)). From here the line proceeds along $M$. teres major and merges proximally to the Angulus caudalis scapula (Figure 3(a), Figure 3(d)) where the fascia
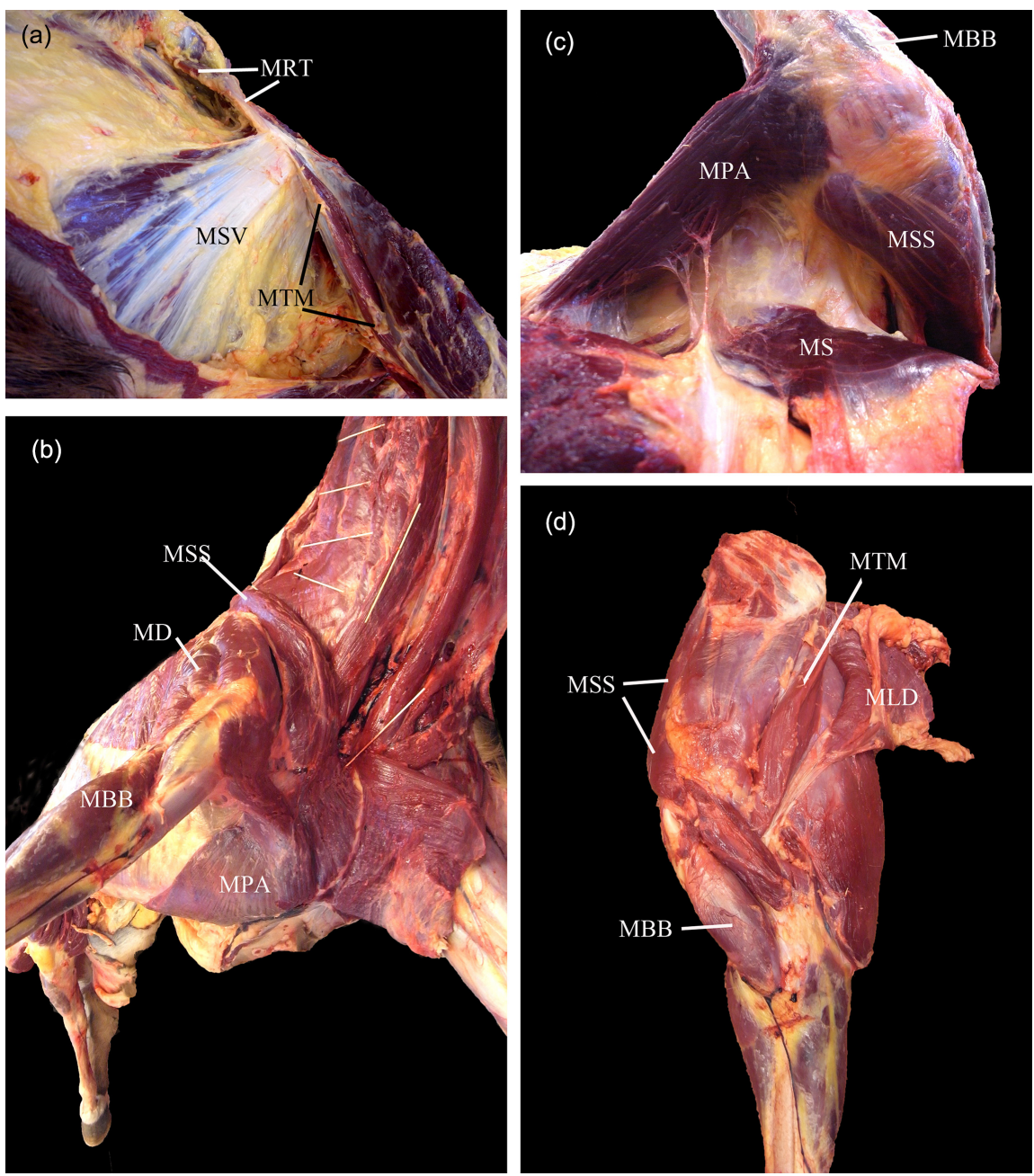

Figure 3. Presents both deep front limb lines for the right front limb (RF). (a) is a caudoventral aspect of the RF with the scapula lifted in an abaxial direction. The scapula is attached to the trunk by the M. serratus ventralis, (MSV). (b) is a cranioventral aspect of the RF. (c) shows a ventral aspect with the front limb lifted in an abaxial direction and (d) shows a medial aspect of the proximal part of a free/loose FL. The FADL is presented in (a) by the continuation between the M. teres major (MTM) and M. rhomboideus thoracis (MRT) in a dorsal direction. In (b) the M. supraspinatus (MSS) and subclavius (MS) continue into a deep fascia sheet running in a caudal direction on the medial side of scapula (b), (c), (d) and continue into the MTM on the caudal aspect of the scapula. The FABL line proceeds from $M$. trapezius (MT) (not presented) into the M. deltoideus (MD) (b) distally and continues in a thin fascia sheet over M. biceps brachii (MBB) (b), (c) in a medial direction to the $M$. pectoralis ascendens (MPA) (b) and further on into the $M$. latissimus dorsi (MLD) (d). 
attaches with tight, strong collagen fibres to both the axial and abaxial side of the Scapula. On the medial side, the fascia continues in a dorsal direction into $M$. rhomboideus thoracis and in a cranio-transverse direction it continues towards the origin of $M$. subclavius. The major function of this myofascial line or sling is to direct the front limb into adduction and an external rotation during the last phase of protraction (Figure 1(b)), just before landing occurs on the caudo-lateral part of the hoof. During the landing phase the direction changes into an internal rotation.

\subsection{The Front Limb Abduction Line (FABL)}

The FABL starts dorsal to the scapula in M. trapezius pars cervicalis and thoracalis and a superficial layer of the Fascia spinocostotransversus s. Lig. dorso-scapularis. This fascia sheet continues in a distal direction on the abaxial side of the scapula into M. deltoideus, which surpasses the craniolateral part of the Articulatio humeri towards the Tuberositas deltoideus humeri (Figure 3(b)). A fascia sheet continues from here in a medial direction over M. biceps brachii (Figure 3(b), Figure $3(\mathrm{c})$ ). The fascia continues in an axial direction and blends into $M$. pectoralis ascendens (Figure $3(\mathrm{~b})$ ) and proceeds in the sagittal plane into the most cranial part of the aponeurosis of M. latissimus dorsi. From here the myofascial line returns in a dorsal direction into M. trapezius and the Dorsal scapular ligament. The major function of this line is to abduct and internally rotate the front limb during the final phase of retraction and the push off.

\subsection{Deep Dorsal Line (DDL)}

The counterpart to the DVL is the Deep Dorsal Line (DDL), which has not been described in humans (Figure 1(a), Figures 4(a)-(d)). The line originates in the coccygeal region in the dorsal muscle compartments of the tail. The $M$. sacrocaudalis (coccygeus) dorsalis medialis (Figure 4(a), Figure 4(d)), which cranially continues to the Mm. mulitifidi (origo S2/3), and the M. sacrocaudalis dorsalis lateralis, which continues in the space between Mm. multifidi and M. longissimus lumborum at L6, are all parts of the line. In a caudoventral direction at the level of the Tuber ischiadicum the DDL connects to the SDL in two ways: 1) a fibrous contact between the caudal part of M. biceps femoris and the epimysium of $M$. sacrocaudalis medialis, and 2) a connection between $M$. semitendinosus (endo- and perimysial contact) and $M$. sacrocaudalis lateralis. In a cranial direction the line joins the myofascia of the transversospinal system e.g. Mm. multifidi (Figure 4(a), Figure 4(b), Figure 4(c)), which span with five fans over one, three and five vertebrae, respectively [39] [40], along the spine until $\mathrm{C} 2$. Here it proceeds into the epaxial suboccipital muscles, $M$. rectus capitis major and minor and M. obliquus capitis caudalis et cranialis of which the latter attaches additionally to the Crista occipitalis. The suboccipital muscles connect to both the atlanto-occipital and atlanto-axial membranes which again connect to the dura mater, the so-called myodural bridges (Figure 2(b) [41]). Similar connections are found in the dorsal intervertebral foraminae along the whole spine. 

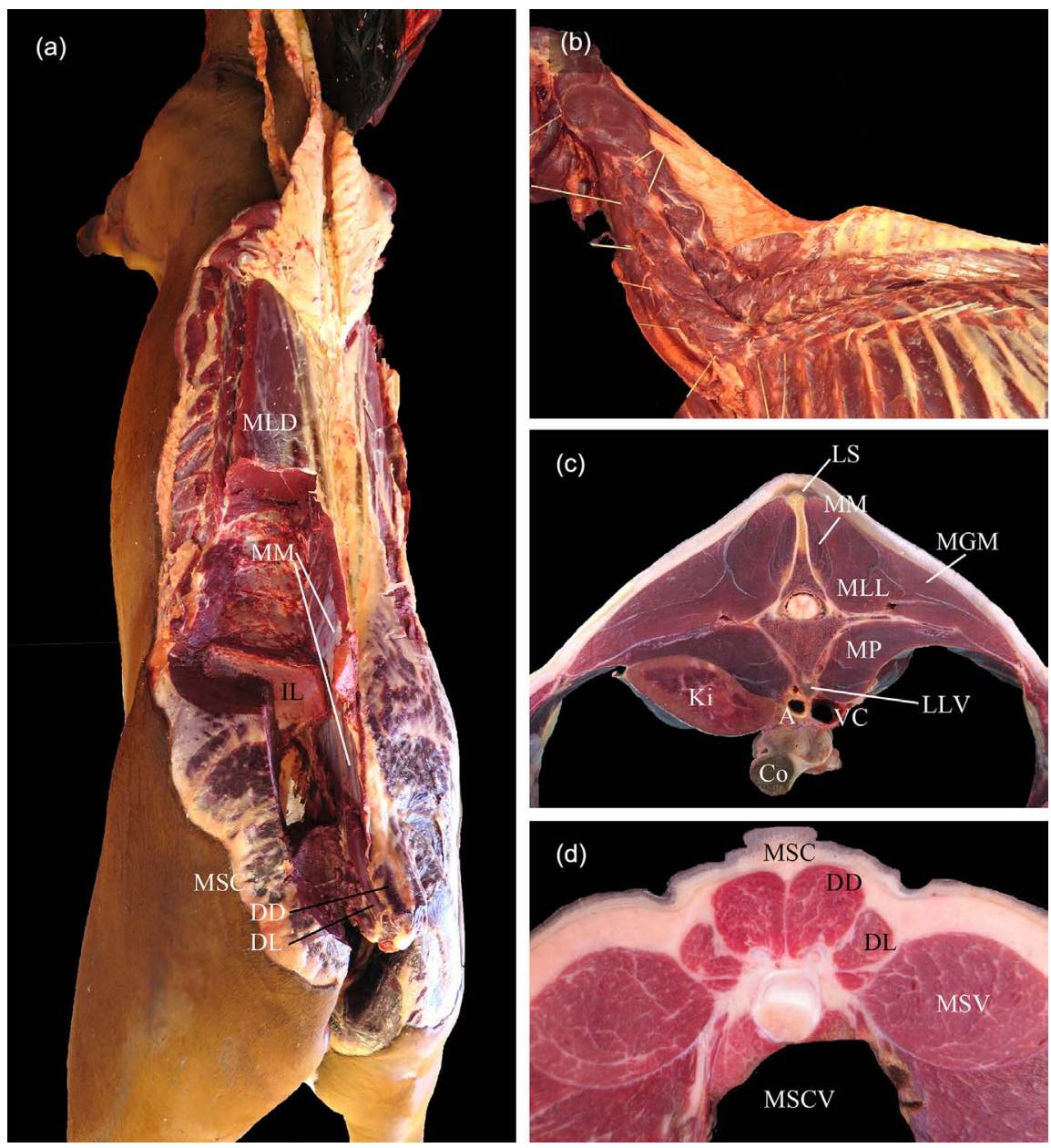

Figure 4. Presents the DDL and parts of the DVL. (a) is a caudodorsal perspective of a dissected horse. On the left side $M$. longissimus lumborum is removed and $M$. longissimus thoracis (MLT) is still present. The Ala ilii (IL) is exposed and the lumbar and sacral part of $M$. multifidus, overlayed by fascia, are presented. The investment of the tail muscles, the M. sacrococc. dorsalis (MSC) pars dors. $(D D)$ and pars lat. $(D L)$ are visible at the caudal end; (b) shows parts of the spinocostotransversal system, the $\mathrm{Mm}$. multifidi $(M M)$ and $M$. intertransversarii (MI). The Lig. supraspinosus continues dorsally into the Lig. nuchae (LN); (c) is a caudal aspect of the transverse section of the lumbar region at the segment of L2/L3. The section presents the epaxial DDL with the $M$. multifidi (MM) and the Lig. supraspinosus (LS), and the hypaxial DVL represented by the M. psoas (MP), the subserosal tissue of the left kidney (Ki), the Aorta(A), the Vena cava (VC) and the Colon (Co) as well as the Lig. longitudinalis ventralis (LLV) are also shown; (d) is a transverse section at the level of the cocc. vertebrae $1 / 2$. Notice how the DDL with the M. sacrococc. dorsalis (MSC), lateral (DL) and medial (DM) is arranged dorsal to the vertebrae with the $M$. sacrococc. ventralis (MSCV) belonging to the DVL ventrally.

From the sacral region the line also extends into the intervertebral ligaments and dorsally into the fibrous Lig. supraspinale (Figure 3(c)). It continues in a cranial direction on top of the spinous processes and continues into a transitional zone into a more elastic composition at the level of Th3-Th9, continuing into the Lig. nuchae (Figure 3(b)). The Funiculus nuchae, of the Lig. nuchae, continues cranially and attaches to the Crista occipitalis ventral and medial to M. semispinalis. 
The Lamina nuchae splits from the funiculi and attaches to the cervical spinous processes (C2 to C5 (C6-7)).

A left as well as a right DDL is present although they run in close proximity. The function of the DDL is to take part in the proprioception and the movement (extension, rotation, and lateral flexion) and stabilization of the vertebrae [14] [39] [42] [43] and thereby the whole spine. The DDL has a close connection to the dura mater both through the myodural bridges but also through the close connection to the Os sacrum [41].

\section{Discussion}

The aim of this study was to dissect and visualize the profound equine kinetic myofascial lines in continuation with the superficial lines previously described [1]. The first two hypotheses studied have their base in the human lines presented by [2] namely the Deep Front Line and the Deep Arm Lines. The third hypothesis that this study has focused on is derived from own practical experiences and observations of the locomotion system as well as the posture of horses, namely the Deep Dorsal Line, which serves to join the spinocostotransversal muscle system. In all of the lines presented [2] we found and observed that the quadruped posture influenced the anatomy and the function of the lines as well as their composition.

\subsection{DVL and DDL}

The present study has confirmed the presence of an equine DVL very similar to that of the human Deep Front Line [2]. According to Myers [2] the line comprises three major divisions: two end parts (the legs and the neck) mostly related to the somatic body system as also seen in the superficial lines, and one middle part, a "true 3-D part" (the cavum pelvis, abdominis and thoracis) mostly related to the visceral system of the body.

Several differences between the human (DFL) and equine DVL lines are present and many of them are influenced by the postural difference, biped versus quadruped. One is the inclusion of the $M$. sartorius in the horse. This connection brings the medial fascia genus in close contact to $\mathrm{Mm}$. psoas and the hypaxial surface of the lumbar vertebrae. The importance of the equine $\mathrm{Mm}$. psoas has been shown by Hyytiäinen et al. [43], who found a muscle fiber composition that indicates that besides flexion of the lumbo-sacral region and flexion of the hip, these muscles act as stabilisers of the lumbar region. The movement or tension from the hind quarter passes directly into the hypaxial compartment of the trunk via the psoas muscles in a cranial direction onto the thoracolumbar junction, where the psoas muscles (origo at the lower thoracic vertebrae) overlap with the diaphragm approaching from a cranial direction (see Figure 2(b), Figure 2(c)). In this region vital structures are situated in close proximity such as the Truncus sympathicus, N. vagus, Ductus thoracicus, Aorta and $V$. azygos dexter. Biomechanically, the thoraco-lumbar region with the 
anticlinal vertebrae Th 14-15-16, are vulnerable as the intervertebral movements change gradually from mainly flexion and extension in the lumbar region to include also lateral flexion coupled to axial rotation in the thoracic region [14]. It is at this point that the line changes from being mostly related to somatic/locomotive structures into more visceral.

In a review [44] and in a study with manipulation of the thoracolumbar region Haussler et al. [45] discussed and showed that reduced movement in the lumbosacral junction transmitted the major movement of the spine into the thoracolumbar junction. The biomechanical consequence of such an overload at this junction has to our knowledge not been studied further. Nor have we been able to find research studies on the influence on equine performance, e.g. the respiration, the functionality of the diaphragm, the regulation of the autonomic nervous system, and thereby the regulation of the inner organs etc. When dissecting the profound and the subserosal fascia, the physical tightness between the organs and somatic structures raises questions about the role of the fascia in these viscerosomatic interactions. As presented in Table 1, numerous equine viscerosomatic fascial contacts are present in the line. According to the histological studies [13] clear differences in the composition of the layers of human organ fascia reflect a possible relation to the somatic part of the body. To explore this further there is now a need for more detailed studies of the equine visceral/organ fascia.

The close connection between Mm.psoas and Crus diaphragmatis at the thoraco-lumbar junction makes the diaphragm a very central muscle and not only a divider between the thorax and the abdomen, but also a factor influencing respiration via the somatic body from a distance. Myers [2] explains how the pulling parts of the line in the legs (deep flexor muscles and adductors) are involved in coordinating a rhythm between respiration and locomotion in humans. A feature well known as e.g. in the gallop the push-off and extension of the trunk in the suspensory phase induces an inspiration, whilst landing, the flexion and collection phases induce an expiration [46].

Looked at from another perspective, a respiratory lung problem or rib cage trauma (influencing the function of the diaphragm) could potentially interact with mobility in the hindquarters. The connection between female urogenital or kidney problems to lumbar pain is a frequent condition seen in horses and it makes good sense when studying the subserosal connections to both the hypaxial muscles but also to the fascia connecting to the lateral raphe in the lumbar region.

Minor adaptations in the organ topography are observed with changes in posture, just as well in horses as in humans. In humans, the gastrointestinal tract is connected to the subvertebral region via the mesenterium (which in terms of human anatomy is now included as a separate organ/a fascia organ in Grey's Anatomy [47]. Similarly, in horses the mesenterium attaches the gastrointestinal tract to the dorsum of the abdominal cavity [15] [16]. 
Denoix and Paillioux [14], illustrates in their book the interplay between viscera and the locomotion system. They explain that the abdomino-pelvic cavity is to be looked upon as an abdominal chamber in which the abdominal muscles contract against the resistance in the chamber created by the diaphragm and internal organs as also [46]. An interaction between the back muscles (SDL and DDL) as well as the abdominal muscles (SVL, LL, SP, FL) and the viscera, balances the forces and pressure both in and on the "abdominal chamber". This illustration supports our approach of how the superficial lines with their structures outbalance the deep ventral line (DVL).

In the thoracic cavity the lungs in both humans and horses are attached to the mediastinum. The attachment of the heart, in contrast, differs between these two species as does the anatomical posture. In humans the apex of the heart "rests" on the Centrum tendineum of the diaphragm and in the horse on the mid sternebrae. The equine heart, which is situated in a ventrodorsal direction, is attached to the sternum via the sternopericardial ligament including the endothoracic fascia. This fascial structure continues within the pericardial sac to the dorsum of the heart and further dorsally via the dorsal mediastinum to the subvertebral fascial structures of the mid thoracic vertebrae. The embryological development of the pleural serosa and subserosa, the formation and development of the pleura-pericardial folds and the enclosure of the endothoracic fascia can all explain this close connection [48]. Besides the two other ventrodorsal connections (thoracic and pelvic diaphragm) the equine epicardial ventrodorsal connection is the third of this kind present between the dorsum and the venter of the horse.

It might reasonably be argued as to whether $\mathrm{Mm}$. scalenus should be part of the line as described in humans [2], spanning as it does from the first rib to $\mathrm{C} 3$ [49]. In horses $M$. scalenus medialis spans from the costa prima to C7 and $M$. scalenus ventralis spans from the costa prima to C4 - C7 [16]. Especially the medial scalene does not follow the rule of dissection [2] of multiple joint muscles, however, their close proximity to the Apertura thoracis cranialis and the fascial attachment to the trachea makes it difficult to separate them from the DVL. These muscles are especially important because the plexus brachialis passes between their ventral and medial parts. Thus, should these muscles be kept in a state of static contraction, they could quite easily have a considerable impact on the neurological efferent and afferent output to and from the front extremities.

The Apertura thoracis cranialis is a region in which the wide and complicated part of the 3-dimensional DVL transmits from the thoracic cavity and into a more pulling part of the line through the cervical region. The region is important as the aperture surrounds the en- and extrance of vital organs and connections (included in the DVL), but also because all other myofascial lines (see Table 2) but the FL embrace and outbalance this region. Additionally, the Columna vertebralis is arranged here in a secondary curve, the extension curve, 
Table 2. Lines related to, as well as involved in the closure of the Apertura thoracis cranialis.

\begin{tabular}{cc}
\hline Lines & Structures \\
\hline SDL & M. longissimus. thor. et cerv. M. spinalis \\
DDL & Mm. spinocostotranv., lig. nuch. \\
DVL & M. longus colli, Fascia cervicalis, M. scalenus \\
SVL & M. sternomand., M. rectus thoracis \\
LL & M. splenius, M. brachiocephalicus, M. omotransv. \\
SP & M. rhomb. cerv., M. serratus ventralis pars cerv., \\
FLPL & M. longissimus dorsi, M. spinalis \\
FLRL & M. brachiocephalicus, M. omotransversarius \\
FADL & M. trapezius et rhomboideus. pars cerv. \\
FABL & M. pectoralis transv. et desc. \\
\end{tabular}

which compresses the intervertebral joints. Stabilisation and balance in this region are important. This is shown in numerous studies of the effect of head and neck position on the performance and gaits [50] [51] [52] [53] [54], which also comprise the structures in the cranial part of the DVL including the tongue, the pharynx, the larynx, the hyoid, the guttural pouch etc. Additionally, the line attaches the biomechanical collaboration as presented by the stomatognatic system [55] balancing from within, the outer equine superficial myofascial lines (SDL, SVL, LL, SL, FLPL).

The flow of the DVL to the head follows the fascia in the neck and continues ventrally to the cranium, where it attaches to several of the cranial bones which in e.g. the craniosacral and osteopathic techniques are approached to influence the pulsation of the cerebrospinal fluid [56].

Influence on the cerebrospinal pulsation is also assumed to be supported by the MDBs situated in the atlanto-occipital and atlanto-axial regions. These structures are important parts of the DDL, and the pumping mechanism is influenced by the $M$. rectus capitis major and minor as well as the cranial and caudal oblique capital muscles and the Lig. nuchae, which in the horse is well developed [41].

The DDL balances the DVL around the Columna vertebralis. In humans a Deep Back Line has not been defined [2]. The reason for this according to Myers (personal communication) is due to a lack of connections between Columna vertebralis and the hindlimb. Although, these connections are clearly visible in the horse as the myofascia of the coccygeal muscles are connected to the myofascia from $M$. biceps femoris and M. semitendinosus, both relate to the SDL and biceps also to the SL. In a cranial direction the line includes the longitudinal spinocostotransversal system of the Columna vertebralis and has an 
influence on proprioception, balance and mobility of the vertebrae as well as strengthening this part of the core system. Indeed, in support of this function, lumbar pain has been found to be associated with a reduction in the cross-sectional area of the M. multifidi [39] [40] [57] [58].

From the tail and in a cranial direction the Lig. supraspinosus is the most dorsal part of the DDL. The ligament conjoins the movements of the vertebrae. It is fibrous until the lower part of the cervicothoracic junction where it transforms into the Lig. nuchae. This ligament supports the cervical vertebrae and the cranium in locomotion, especially in relation to the oscillation of the head during walking. In modern horse breeds the laminae nuchae reach from C2 to C5 [59], whereas in many anatomical descriptions (perhaps of older date) the laminae attach to all the cervicals up to C6-C7 [15] [16]. The lack of the lower laminae nuchae increases the vulnerability of the cervicothoracic region as also mentioned previously.

\subsection{Front Limb Lines}

The armlines (human) and front limb lines (horses) are influenced by not only a difference in posture but also by biomechanics. In the quadruped horse a vertical line of balance goes from the proximal third part of the scapula to the mid region of the hoof. This line divides the front limb into a protraction and a retraction compartment [1]. The line of balance is essential in the mechanical stay apparatus of the front limb, where it among other things secures the horse, enabling it to stand and rest in balance with only minor energy consumption and without overuse of the anatomical structures. In the brachium, antebrachium and the foot the FLPL is mostly represented dorsally by the extensor muscles and tendons. The flexor muscles and tendons represent the FLRL. A cross-over of the pro- and retraction lines at a point close to the top third of the scapula indicates the location of the pivot joint, the thoraco-scapular joint. This joint is the centre of motion in the front limb and the top point for the line of balance as mentioned above. The thoracic sling which is composed of only muscular and tendinous attachments between the front limb and the thorax supports free and flexible movements including both pro- and retraction, but also and in majority in this region facilitates ad- and abduction as well as in- and outward rotation, thereby providing a functional reason for the anatomical location of the deep front limb lines.

The equine deep front limb lines connect to numerous other structures and lines such as: M. rhomboideus (SP, FLPL and FLRL), M. trapezius (FLPL, FLRL), M. serratus ventralis (SL), M. latissimus dorsi (FL), M. pectoralis ascendens (FLRL, FL) (see Table 3). Thus, in situations where there is a change in motion pattern in the front limbs, compensatory motion can affect other lines through these connections, contributing to imbalance. In this way it is easy to understand how front limb imbalance can interfere with the posture of the rest of the body and vice versa. Indeed, just such an interaction could explain the compensatory 
Table 3. Structures shared by the FADL respectively, the FABL and other equine kinetic myofascial lines.

\begin{tabular}{ccc}
\hline Line & Structure & Connecting line \\
\hline FADL & M. supraspinatus & FLPL \\
& M. rhomboideus thor. & SL \\
\hline M. trapezius & FLRL \\
FABL & pars cervicis & FLPL \\
& pars thoracis & SVL, FL \\
& M. pect. ascendens & FLRL, FL \\
\hline
\end{tabular}

weight shift in the body and towards the front limbs that occurs with changes in head posture. Moreover, a reduction in the mobility of the lumbosacral junction results in a reduction in the motion of the lumbar region whilst increasing a translocation of movement in cranial direction towards the front part of the horse [44].

So, stepping back for just a moment and considering what has been presented in this study, it is important to re-visualize the myofascial lines as being arranged in the form of a 3D skeleton, which spans the entire body, and serves to counteract changes in tension whilst attempting to balance the body, according to the tensegrity model, while maintaining a new posture or facilitating motion. Of course, under normal conditions this is how the myofascial lines interact, enabling parts of the lines to move freely in relation to other lines or structures at all times.

\section{Conclusion}

The Deep Ventral Line of the horse closely resembles the Deep Front Line described by Myers [2] in humans. The two deep Front Limb Lines are different from the human deep arm lines, just as the FLPL and FLRL are, due to their very different anatomy and function, bipeds versus quadrupeds. The deep front limb lines show a closer interaction with the Front Limb Protraction and Retraction Lines described [1], than they do with the superficial and deep arm lines in humans. Finally, whilst Myers [2] discussed the existence of a Deep Back Line in humans, concluding that it is not present since he was unable to find any connection to the limbs, this study has identified the presence of a Deep Dorsal Line in the horse, as supported by a clear connection with the hindlimbs.

\section{Acknowledgements}

The study was supported in part of the Danish Foundation of Promotion of Veterinary Science and the IVCA (The International Veterinary and Chiropractic Association). There are from the funds no conflicts of interest, influence on the 
research nor on the content of the submitted manuscript. The authors would like to thank the technical staff at IVH, Faculty of Health \& Medical Sciences, Copenhagen for their assistance; Mette Bloch Christiansen for photography/illustrations and permission to paint her horse; Dr. Adrian P. Harrison for proofreading and not least the owners of the horses for their generous donation.

\section{Author Contribution}

VSE and RMS designed the project, contributed data, analysed the data, made the figures and wrote the manuscript.

\section{Conflicts of Interest and Data Sharing}

The authors are not aware of any conflicts of interest associated with this study. VSE is employed full-time in the Faculty of Health \& Medical Sciences and RS is self-employed-neither authors received any payment for their work, nor was this study sponsored commercially.

The authors have not shared data alongside in other research publications.

\section{References}

[1] Elbrønd, V.S. and Schultz, R.M. (2015) Myofascia-The Unexplored Tissue: Myofascial Kinetic Lines in Horses, a Model for Describing Locomotion Using Comparative Dissection Studies Derived from Human Lines. Medical Research Archives, No. 3. https://doi.org/10.18103/mra.v0i3.125

[2] Myers, T.M. (2013) Myofascial Trains. Myofascial Meridians for Manual and Movement Therapists. 3rd Edition, Elsevier Health Sciences, London.

[3] Procacci, P. and Maresca, M. (1999) Referred Pain from Somatic and Visceral Structures. Current Review of Pain, 3, 96-99. https://doi.org/10.1007/s11916-999-0032-y

[4] Giamberardino, M.A., Affaitati, G. and Costantini, R. (2006) Referred Pain from Internal Organs. In: Cervero, F. and Jensen, T.S., Eds., Handbook of Clinical Neurology, Elsevier, Amsterdam, Chapter 24, 343-361. https://doi.org/10.1016/S0072-9752(06)80028-X

[5] Vecchiet, L.J. and Giamberardino, M.A. (1999) Referred Muscle Pain: Clinical and Pathophysiologic Aspects. Current Review of Pain, 3, 489-498. https://doi.org/10.1007/s11916-999-0077-y

[6] Oliva-Pascual-Vaca, Á., González-González, C., Oliva-Pascual-Vaca, J. and Piña-Pozo, F. (2019) Visceral Origin: An Underestimated Source of Neck Pain. A Systematic Scoping Review. Diagnostics (Basel), 9, 186. https://doi.org/10.3390/diagnostics9040186

[7] Silva, A.C.O., Biasotto-Gonzalez, D.A. and Oliveira, F.H.M. (2018) Effect of Osteopathic Visceral Manipulation on Pain, Cervical Range of Motion, and Upper Trapezius Muscle Activity in Patients with Chronic Nonspecific Neck Pain and Functional Dyspepsia: A Randomized, Double-Blind, Placebo-Controlled Pilot Study. Evidence-Based Complementary Alternative Medicine, 2018, Article ID: 4929271. https://doi.org/10.1155/2018/4929271

[8] Kellgren, J. (1939) On the Distribution of Pain Arising from Deep Somatic Structures with Charts of Segmental Pain Areas. 
[9] Garrison, D.W., Chandler, M.J. and Foreman (1992) Viscerosomatic Convergence onto Feline Spinal Neurons from Esophagus, Heart and Somatic Fields: Effects of Inflammation. Pain, 49, 373-382. https://doi.org/10.1016/0304-3959(92)90245-7

[10] Gwirtz, P., Dickey, J., Vick, D., Williams, M. and Foresman, B. (2007) Viscerosomatic Interaction Induced by Myocardial Ischemia in Conscious Dogs. Journal of Applied Physiology (Bethesda, Md.: 1985), 103, 511-517. https://doi.org/10.1152/japplphysiol.00495.2006

[11] MacKenzie, J. (1893) Some Points Bearing on the Association of Sensory Disorders and Visceral Disease. Brain, 16, 321-353. https://doi.org/10.1093/brain/16.3.321

[12] Beal, M.C. (1985) Viscerosomatic Reflexes: A Review. The Journal of the American Osteopathic Association, 85, 786-801.

[13] Stecco, C., Sfriso, M.M., Pozionato, A., Rambaldo, A., Albertin, G., Macchi, V. and De Caro, R. (2017) Microscopic Anatomy of the Visceral Fasciae. Journal of Anatomy, 231, 121-128. https://doi.org/10.1111/joa.12617

[14] Denoix, J.-M. and Paillioux, J.-P. (2009) Physical Therapy and Massage for the Horse. Biomechanics, Exercise, Treatment. 2nd Edition, Manson Publishing, Hong Kong.

[15] Nickel, R., Schummer, A. and Seiferle, E. (1968) Lehrbuch der Anatomie der Haustiere, Band I, Bewegungsapparat. Paul Parey, Berlin, Hamburg.

[16] König, H.E. and Liebich, H.-C. (2014) Veterinary Anatomy of Domestic Mammals. Textbook and Colour Atlas. 6th Edition, Schattauer, Stuttgart.

[17] Yucesoy, C.A. and Huijing, P.A. (2007) Substantial Effects of Epimuscular Myofascial Force Transmission on Muscular Mechanics Have Major Implications on Spastic Muscle and Remedial Surgery. Journal of Electromyographic Kinesiology, 17, 664-79. https://doi.org/10.1016/j.jelekin.2007.02.008

[18] Carvalhais, V.O.D.C., Ocarino, J.D.M., Araújo, V.L., Souza, T.R., Silva, P.L.P. and Fonseca, S.T. (2013) Myofascial Force Transmission between the Latissimus Dorsi and Gluteus Maximus Muscles: An in Vivo Experiment. Journal of Biomechanics, 46, 1003-1007. https://doi.org/10.1016/j.jbiomech.2012.11.044

[19] Tian, M., Herbert, R.D., Hoang, P., Gandevia, S.C. and Bilston, L.E. (2012) Myofascial Force Transmission between the Human Soleus and Gastrocnemius Muscles during Passive Knee Motion. Journal of Applied Physiology, 113, 517-523. https://doi.org/10.1152/japplphysiol.00111.2012

[20] Huijing, P.A., Yamann, A., Ozturk, C. and Yucesoy, C.A. (2011) Effects of Knee Joint Angle on Global and Local Strains within Human Triceps Surae Muscle: MRI Analysis Indicating in Vivo Myofascial Force Transmission between Synergistic Muscles. Surgical Radiological Anatomy, 33, 869-879. https://doi.org/10.1007/s00276-011-0863-1

[21] Yucesoy, C.A., Baan, G. and Huijing, P.A. (2010) Epimuscular Myofascial Force Transmission Occurs in the Rat between the Deep Flexor Muscles and Their Antagonistic Muscles. Journal of Electromyography and Kinesiology, 20, 118-126. https://doi.org/10.1016/j.jelekin.2008.09.012

[22] Huijing, P.A. and Baan, G.C. (2008) Myofascial Force Transmission via Extramuscular Pathways Occurs between Antagonistic Muscles. Cells Tissues Organs, 188, 400-414. https://doi.org/10.1159/000118097

[23] Kjær, M., Langberg, H., Heinemeier, K., Bayer, M.L., Hansen, M., Holm, L., Doessing, S., Kongsgaard, M., Krogsgaard, M.R. and Magnusson, S.P. (2009) From Mechanical Loading to Collagen Synthesis, Structural Changes and Function in Human Tendon. Scandinavian Journal of Medicine and Science in Sports, 19, 
500-510. https://doi.org/10.1111/j.1600-0838.2009.00986.x

[24] Schleip, R., Klingler, W. and Lehmann-Horn, F. (2006) Fascia Is Able to Contract in Smooth Muscle-Like Manner and Thereby Influence Musculoskeletal Mechanics. Proceedings from the 5 th World Congress of Biomechanics, Medimond International Proceedings, Munich, 51-54. https://doi.org/10.1016/S0021-9290(06)84993-6

[25] Schleip, R., Naylor, I.L., Ursu, D., Meizer, W., Zorn, A., Wilke, H.-J., Lehmann-Horn, F. and Klingler, W. (2006) Passive Muscle Stiffness May Be Influence by Active Contractility of Intramuscular Connective Tissue. Medical Hypotheses, 66, 66-71. https://doi.org/10.1016/j.mehy.2005.08.025

[26] Van De Water, L., Varney, S. and Tomasek, J.J. (2013) Mechanoregulation of the Myofibroblast in Wound Contraction, Scarring, and Fibrosis: Opportunities for New Therapeutic Intervention. Advances in Wound Care (New Rochelle), 2, 122-141. https://doi.org/10.1089/wound.2012.0393

[27] Klingler, W., Velders, M., Hoppe, K., Pedro, M. and Schleip, R. (2014) Clinical Relevance of Fascial Tissue and Dysfunctions. Current Pain and Headache Reports, 18, 439. https://doi.org/10.1007/s11916-014-0439-y

[28] Magnusson, S.P., Langberg, H. and Kjaer, M. (2010) The Pathogenesis of Tendinopathy: Balancing the Response to Loading. Nature Reviews Rheumatology, 6, 262-268. https://doi.org/10.1038/nrrheum.2010.43

[29] Neuberger, A. and Slack, H.G. (1953) The Metabolism of Collagen from Liver, Bone, Skin and Tendon in the Normal Rat. Biochemical Journal, 53, 47-52. https://doi.org/10.1042/bj0530047

[30] Staubesand, J. and Li, Y. (1996) Zum Feinbau der Fascia cruris mit besonderer Berücksichtigung epi-und intrafaszialer Nerven. Manuelle Medicin, 34, 196-200.

[31] Benetazzo, L., Bizzego, A., De Caro, R., Frigo, G., Guidolin, D. and Stecco, C. (2011) 3D Reconstruction of the Crural and Thoracolumbar Fasciae. Surgical and Radiological Anatomy, 33, 855-862. https://doi.org/10.1007/s00276-010-0757-7

[32] Stecco, C., Pavan, P.G., Porzionato, A., Macchi, V., Lancerotto, L., Carniel, E.L., Natali, A.N. and De Caro, R. (2009) Mechanics of Crural Fascia: From Anatomy to Constitutive Modelling. Surgical and Radiological Anatomy, 31, 523-529. https://doi.org/10.1007/s00276-009-0474-2

[33] Ahmed, W., Kulikowska, M., Ahlmann, T., Berg, L.C., Harrison, A.P. and Elbrønd, V.S. (2019) A Comparative Multi-Site and Whole-Body Assessment of Fascia in the Horse and Dog: A Detailed Histological Investigation. Journal of Anatomy, 235, 1065-1077. https://doi.org/10.1111/joa.13064

[34] Stecco, C., Stern, R., Porzionato, A., Macchi, V., Masiero, S., Stecco, A. and De Caro, R. (2011) Hyaluronan within Fascia in the Etiology of Myofascial Pain. Surgical Radiology and Anatomy, 33, 891-896. https://doi.org/10.1007/s00276-011-0876-9

[35] Stecco, C., Fede, C., Macchi, V., Porzionato, A., Petrelli, L., Biz, C., Stern, R. and De Caro, R. (2018) The Fasciacytes: A New Cell Devoted to Fascial Gliding Regulation. Clinical Anatomy, 31, 667-676. https://doi.org/10.1002/ca.23072

[36] Lee, J.Y. and Spicer, A.P. (2000) Hyaluronan: A Multifunctional, megaDalton, Stealth Molecule. Current Opinion in Cell Biology, 12, 581-586. https://doi.org/10.1016/S0955-0674(00)00135-6

[37] Budras, K.-D., Sack, W.O. and Röck, S. (2008) Anatomy of the Horse. 5th Edition, Schlüterche Verlagsgeselschaft GMBH and Co., Hannover.

[38] Schaller, O. and Constantinescu, G. (2012) Illustrated Veterinary Anatomical Nomenclature. 3rd Edition, Enke Verlag, Stuttgart. 
[39] Stubbs, N.C., Riggs, C.M., Hodges, P.W., Jeffcott, L.B., Hodgson, D.R., Clayton, H.M. and McGowan, C.M. (2010) Osseous Spinal Pathology and Epaxial Muscle Ultrasonography in Thoroughbred Racehorses. Equine Veterinary Journal, 42, 654-661. https://doi.org/10.1111/j.2042-3306.2010.00258.x

[40] Stubbs, N.C., Hodges, P.W., Jeffcott, L.B., Cowin, G., Hodgson, D.R., McGowan, C.M., Stubbs, N.C., et al. (2010) Functional Anatomy of the Caudal Thoracolumbar and Lumbosacral Spine in the Horse. Equine Veterinary Journal, 38, 19-26. https://doi.org/10.1111/j.2042-3306.2006.tb05575.x

[41] Elbrønd, V.S. and Schultz, R. (2019) Equine Myodural Bridges-An Anatomical and Integrative/Functional Description of Myodural Bridges along the Spine of Horses: Special Focus on the Atlanto-Occipital and Atlanto-Axial Regions. Medical Research Archives, 7, 11.

[42] Stubbs, N.C., Kaiser, L.J., Hauptman, J. and Clayton, H.M. (2011) Dynamic Mobilisation Exercises Increase Cross Sectional Area of Musculus Multifidus. Equine Veterinary Journal, 43, 522-529. https://doi.org/10.1111/j.2042-3306.2010.00322.x

[43] Hyytiäinen, H.K., Mykkänen, A.K., Hielm-Björkman, A.K., Stubbs, N.C. and McGowan, C.M. (2014) Muscle Fibre Type Distribution of the Thoracolumbar and Hindlimb Regions of Horses: Relating Fibre Type and Functional Role. Acta Veterinaria Scandinavica, 56, Article No. 8. https://doi.org/10.1186/1751-0147-56-8

[44] Van Weeren, P.R., McGowan, C. and Haussler, K.K. (2010) Science Overview: Development of a Structural and Functional Understanding of the Equine Back. Equine Veterinary Journal, 42, 393-400. https://doi.org/10.1111/j.2042-3306.2010.00207.x

[45] Haussler, K., Hill, A., Puttlitz, C. and McIlwraith, W. (2007) Effects of Vertebral Mobilization and Manipulation on Kinematics of the Thoracolumbar Region. American Journal of Veterinary Research, 68, 508-516. https://doi.org/10.2460/ajvr.68.5.508

[46] Bramble, D.M. (2015) Axial-Appendicular Dynamics and the Integration of Breathing and Gait in Mammal. American Zoologist, 29, 171-186. https://doi.org/10.1093/icb/29.1.171

[47] Coffey, J.C. and O'Leary, D.P. (2016) The Mestentery: Structure, Function, and Role in Disease. The Lancet Gastroenterology and Hepatology, 1, 238-247. https://doi.org/10.1016/S2468-1253(16)30026-7

[48] Hyttel, P., Sinowatz, F. and Vejlsted, M. (2010) Essentials of Domestic Animal Embryology. Saunders, Elsevier, Amsterdam.

[49] Netter, F.H. (2006) Atlas of Human Anatomy. 4th Edition, Saunders, Elsevier, Philadelphia.

[50] Rhodin, M., Johnston, C., Holm, K.R., Wennerstrand, J. and Drevemo, S. (2005) The Influence of Head and Neck Position on Kinematics of the Back in Riding Horses at the Walk and Trot. Equine Veterinary Journal, 37, 7-11. https://doi.org/10.2746/0425164054406928

[51] Rhodin, M., Gómez Alvarez, C.B., Byström, A., Johnston, C., Van Weeren, P.R., Roepstorff, L. and Weishaupt, M.A. (2009) The Effect of Different Head and Neck Positions on the Caudal Back and Hindlimb Kinematics in the Elite Dressage Horse at Trot. Equine Veterinary Journal, 41, 274-279. https://doi.org/10.2746/042516409X394436

[52] Gómez Alvarez, C.B., Rhodin, M., Bobber, M.F., Meyer, H., Weishaupt, M.A., Johnston, C. and Van Weeren, P.R. (2006) The Effect of Head and Neck Position on the Thoracolumbar Kinematics in the Unridden Horse. Equine Veterinary Journal, 
36, 445-451. https://doi.org/10.1111/j.2042-3306.2006.tb05585.x

[53] Lashley, M.J., Nauwelaerts, S., Vernooij, J.C., Back, W. and Clayton, H.M. (2014) Comparison of the Head and Neck Position of Elite Dressage Horses during Top-Level Competitions in 1992 versus 2008. Veterinary Journal, 202, 462-465. https://doi.org/10.1016/j.tvjl.2014.08.028

[54] Go, L., Barton, A.K. and Ohnesorge, B. (2014) Evaluation of Laryngeal Function under the Influence of Various Head and Neck Positions during Exercise in 58 Performance Horses. Equine Veterinary Education, 26, 41-47. https://doi.org/10.1111/eve.12091

[55] Kuryszko, J. and Ayczewska-Mazurkiewicz, S. (2004) Equine Masticatory Organ. Part III. Acta of Bioengineering and Biomechanics, 6, 25-30.

[56] Terem, I., Ni, W.W., Goubran, M. and Rahimi, M.S. (2018) Revealing Sub-Voxel Motions of Brain Tissue Using Phase-Based Amplified MRI (aMRI). Magnetic Resonance in Medicine, 80, 2549-2559. https://doi.org/10.1002/mrm.27236

[57] Hides, J., Gilmore, C., Stanton, W. and Bohlscheid, E. (2008) Multifidus Size and Symmetry among Chronic LBP and Healthy Asymptomatic Subjects. Manual Therapy, 13, 43-49. https://doi.org/10.1016/j.math.2006.07.017

[58] Wallwork, T.L., Stanton, W.R., Freke, M. and Hides, J.A. (2009) The Effect of Chronic Low Back Pain on Size and Contraction of the Lumbar Multifidus Muscle. Manual Therapy, 14, 496-500. https://doi.org/10.1016/j.math.2008.09.006

[59] May-Davis, S. and Kleine, J. (2014) Variations and Implications of the Gross Anatomy in the Equine Nuchal Ligament Lamellae. Journal of Equine Veterinary Science, 34, 1110-1113. https://doi.org/10.1016/j.jevs.2014.06.018 


\section{Abbreviations}

FADL: Front limb adduction line FABL: Front limb abduction line FLPL: Front limb protraction line FLRL: Front limb retraction line SDL: Superficial dorsal line

SVL: Superficial ventral line DDL: Deep dorsal line

DVL: Deep ventral line

LL: Lateral line

SP: Spiral line

FL: Functional line

MDB: Myodural bridge

M: Musculus

Mm: Musculi

$\mathrm{T}$ : Tendino 